УДК 94(540):82-94

\title{
НАЦИОНАЛЬНЫЙ БРЕНДИНГ В ИНДИИ: СТРАТЕГИИ И КАМПАНИИ
}

В современных условиях многополярной модели мироустройства большинство стран стремятся найти и занять лучшую нишу, что требует определенных усилий. Военно-техническое превосходство постепенно перестает играть ключевую роль в достижении этой цели и на первый план выходят торгово-экономические и финансовые механизмы. Увеличивается число исследований, посвященных политики мягкой силы и ее основным инструментам, включая публичную дипломатию. Подобно тому, как различные компании работают над своим имиджем, стремясь создать уникальный бренд, страны пытаются разработать национальные бренды, которые будут узнаваемы во всем мире и обеспечат дополнительные поступления в государственный бюджет.

B научном сообществе уже начинает набирать популярность практика изучения брендов различных стран, выявление причин успехов одних маркетинговых кампаний и неудач других, хотя заметно ощущается недостаточная развитость дефинитивной базы, отечественный исследовательский дискурс практически не сформирован. Индия, несмотря на имеющиеся проблемы внутри страны, прилагает немало усилий для улучшения собственного имиджа в глазах иностранной общественно- сти, а также разработки национального бренда, в связи с чем в настоящей статье предпринимается попытка комплексно рассмотреть основные шаги индийского правительства в ходе выработки стратегии национального брендинга. Рассматривается деятельность правительственных органов по разработке и осуществлению кампании, проводимых в различных областях, включая туризм, медицину, бизнес и культуру с целью создания неповторимого имиджа нации. Хронологические рамки охватывают период с начала 2000-х гг. по настоящее время. Знаковым же событием в данном контексте послужила разработка маркетинговой кампании «Невероятная Индия», положившая начало процессу создания национального бренда страны. В работе приводятся различные данные рейтингов международных служб по оценке брендов современных стран, позволяющие определить место Индии в деле формирования собственного бренда, а также сравнить успехи ее деятельности с другими странами.

Ключевые слова: Индия, публичная дипломатия, национальный брендинг, кампании по брендингу, Невероятная Индия, международный день йоги, конкурентная идентичность, архитектура бренда.

A. A. Tonyan

\section{NATIONAL BRANDING IN INDIA: STRATEGIES AND CAMPAIGNS}

In modern multipolar world model, most countries seek to find and occupy a better niche, which demands certain efforts. Military-technical superiority ceases to play a key role in achievement of this purpose and trade, economic and financial mechanisms come to the forefront. The number of studies on soft power policy and its main tools, including public diplomacy, is increasing. Just as different companies are working on their image, trying to create a unique brand, countries are trying to develop national brands that will be recognizable all over the world and provide additional revenues to the state budget. In the scientific community, the practice of studying brands in various countries is beginning to gain popularity, identifying the reasons for the success of some marketing campaigns and the failures of others, although there is a noticeable lack of development of the definitive framework, the domestic research discourse is practically not formed. India, despite the existing problems in the country, is making considerable efforts to improve its own image in the eyes of foreign public, as well as the develop-

В современную эпоху глобализации, в условиях насаждения единого стандарта потребления и возникновения социокультурной общности человечества, одной из нарастающих тенденций ment of a national brand, and therefore this article attempts to comprehensively review the basic steps of the Indian government in the course of developing national branding strategies. It discusses the activities of government bodies in the development and implementation of campaigns conducted in various areas, including tourism, medicine, business and culture, with the aim of creating a unique image of the nation. The chronological framework covers the period from the beginning of the 2000 s to the present. A landmark event in this context was the development of the marketing campaign "Incredible India", which initiated the process of creating a national brand of the country. The paper presents various data of ratings of international services for the evaluation of brands of modern countries, allowing to determine the place of India in creating its own brand, as well as compare the success of its activities with other countries.

Key words: India, public diplomacy, nation branding branding campaigns, Incredible India, International yoga day, competitive identity, brand architecture.

развития наций является все большее стремление к сохранению своих исконных черт культуры. Особенно заметно данное стремление можно наблюдать в процессе фрормирования и последую- 
щего использования инструментов публичной дипломатии, позволяющей не только сберечь свои историко-культурные ценности, но и поведать о них миру, создав при этом максимально привлекательный образ страны в глазах иностранной публики. В последние несколько десятилетий все больше стран активно начали развивать политику публичной дипломатии и вместе с тем стало популярным создание особого имиджа нации в рамках национального брендинга.

Капиталы есть двигатели глобализации, а бренд города или страны можно рассматривать как капитал, поскольку он добавляет ценность, следовательно, и стоимость всем товарам и услугам продаваемым на территории города или страны. В связи с этим становится крайне актуальным исследование брендов различных территорий, выявление их взаимосвязи с процессами укрепления позиций стран на международной арене.

Пионером концепции национального брендинга является Саймон Анхольт (Simon Anholt) британский исследователь, главный редактор профессионального журнала в области национального брендинга - Брендинг мест и публичная дипломатия (Place Branding and Public Diplomacy) Основная идея британского ученого сводится к тому, что если компании могут создавать свои отличительные торговые марки и разрабатывать бренды, что обеспечивает им узнаваемость на различных уровнях, то и города, регионы и государства способны создать собственные марки и бренды для привлечения иностранных инвестиций в страну и в целом повышения привлекательности конкретной местности за рубежом.

Именно С. Анхольт впервые в 2002 г. употребил термин «брендинг мест» и «национальный брендинг», разработал рейтинги стран на основе проведенных исследований: Индекс национальных брендов (Anholt-Gfk Roper Nation Brands Index). индекс брендов городов (Anholt-Gfk Roper City Brands Index) и т.Д. Графрически свою концепцию он выразил в форме шестиугольника (Branding Hexagon), в котором каждый угол представляет собой параметр измерения национального бренда. К числу этих параметров он отнес: туризм; экспорт; культуру и культурное наследие; людей - как знаменитостей, прославивших нацию, так и местных жителей с точки зрения гостеприимства и дружелюбия; власть; инвестиции и иммиграцию, определяющие способность каждой страны привлекать людей для проживания, учебы или работы.

Таким образом, национальный брендинг - это процесс, при котором создается, контролируется, оценивается и регулируется имидж нации с целью улучшить репутацию страны среди целевой иностранной аудитории [10, р. 96]. Продуктом данного процесса является национальный бренд, выраженный в совокупности ассоциаций, знаков, символов о стране как целостной системе.

Позже, в 2007 г. С. Анхольт ввел понятие «конкурентная идентичность", ее целью является стимулирование инноваций, а уже имеющиеся нововведения рассматриваются как часть стратегии по улучшению имиджа страны на международной арене. Появление конкурентной идентичности и цикла конкурентной идентичности обусловлено тем, что имидж нации не может быть построен из ничего, чтобы был результат необходим «синтез бренд-менеджмента с публичной дипломатией, сопровождаемой активным развитием торговли, инвестиций, туризма и экспорта» [7]

Поскольку представленное научное направление еще очень молодо, то нередко назревают серьезные дискуссии, в частности связанные с категориальным аппаратом данной области знаний. В современной историографии некоторые исследователи и вовсе по-прежнему считают национальный бренд мифом. Сложности исследования в первую очередь связаны с отсутствием общего понимания сути концепций и неверной или неточной трактовкой основных понятий. Так нередко взаимозаменяемыми оказываются такие термины, как национальный бренд и бренд территории, идентичность национального бренда и национальная идентичность, понятия имидж, репутация и идентичность и т.д. ${ }^{1}$

Помимо С. Анхольта концепции брендинга развивали другие не менее известные исследователи, такие как Г. Дули, Дж. Кунде, Д. Боуин, Д. Динни, Д. Девлин и др. Одним из наиболее значимых дополнений в развитии данного направления стало появление «архитектуры бренда», подразумевающего методы, с помощью которых бренд организовывает многочисленные суббренды, такие как туризм, искусство, кухня, нередко также иногда именуемые атрибутами бренда.

Чтобы создать сильный бренд, необходимо сформировать четкий набор атрибутов, присущих стране, на их основе можно сформировать ее позитивное восприятие у целевых аудиторий [1]

На данный момент наиболее успешными в брендинге мест, регионов и наций являются европейские государства и США. Однако осуществить эту сложную задачу по созданию бренда на уровне страны пытаются и многие государства в Африке, Латинской Америке и Азии.

Наиболее популярными инструментами брендинга являются логотипы и слоганы. Часто произносимые в рекламных роликах «Malaysia is truly Asia» (Малайзия - это действительно Азия),

1 Здесь: бренд территории стимулирует экономические интересы (экспорт, туризм, внутренние инвестиции), а национальный бренд связан с целостным представлением о стране на международной арене, рассматривая политические, экономические и культурные аспекты; Национальная идентичность означает коллективное осознание нацией своих особенностей и отличий от других, а также включает в себя чувство принадлежности к нации. А идентичность бренда - это набор ассоциаций, которые бренд-стратег стремится создать или сохранить, используя визуальные символы и логотипы, олицетворяющие бренд. Как страна может иметь несколько брендов, так и может быть несколько идентичностей бренда, в то время как национальная идентичность одна; Имидж нации - это то, что народ данной страны стремится донести до всего мира касательно самих себя, идентичность - это самовосприятие нации, а репутация - тот отзыв, который она получает от внешнего мира. 
«Dubai is the Jewel in the Desert» (Дубай - Жемчужина в пустыне), «Amazing Thailand» (Удивительный Таиланд), «Bolivia: The Authentic still Exists» (Боливия: Подлинное еще существует), «Sri Lanka: The Pearl of the Indian Ocean» (Шри-Ланка: Жемчужина Индийского океана) или (Incredible !ndia» (Невероятная Индия) запомнились миллионам людей во всем мире.

Задача национального брендинга в Индии возложена на «Фонд ценности бренда Индии» (The India Brand Equity Foundation) и сводится к продвижению и развитию международной осведомленности о лейбле «Made in India», а также содействию распространению знаний об индийских товарах и услугах. Фонд образован правительством страны как средство поощрения инвестиций для продвижения «Бренд Индия» и соответственно все проводимые кампании финансируются им, представляя Индию как огромный рынок товаров и услуг и выгодное место для инвестиций.

Одной из самых популярных международных маркетинговых кампаний Фонда стала «Невероятная Индия», проводимая с 2002 г., задачей которой явилось продвижение туризма в Индии на глобальный уровень. Автором названия является Амитабх Кант, исполнительный директор «Национального института преобразования Индии») (National Institution for Transforming India, NITI Aayog), аналитического центра, созданного в 2015 г. при правительстве страны. Прилагательное «невероятная» в отличие от «красивая" или иных легко востребованных слов имеет особое значение, подчеркивая интенсивные темпы экономического развития страны, разнообразие культур, языков, ландшастов и кухонь.

В большинстве случаев бренд получил положительные отзывы и сумел выполнить свою задачу: доходы от туризма выросли с 3,4 млрд долларов в 2000 году на 11,7 млрд долларов в 2008 г. [15].

Несмотря на то, что организацией данной маркетинговой компании занималось Министерство туризма, а ее целью являлось выведение Индии на международный туристический рынок, А. Кант не считает ее суббрендом. В своей книге «Брендинг Индии: Невероятная история) (Branding India: An Incredible story), он подробно повествует о кампании, превратившей «спящего гиганта» в одно из самых желанных мест для отдыха и путешествий в мире. Кампания была сосредоточена на идее достижения «высшего качества жизни для индийцев через туризм, что обеспечило бы уникальную возможность для фризического оживления, умственного омоложения, культурного обогащения и духовного подъема» $[15$, р. 6].

«Невероятная Индия» становится глобальной маркетинговой кампанией, ее рекламу можно было увидеть даже в общественном транспорте Лондона и Нью-Йорка, она обсуждалась практически на всех телеканалах, таких как ITV, Sky, BBC, Channel 4 и CNN, а также на радиостанциях и цифровых СМИ. А. Кант утверждает, что приблизительный доход от рекламы составил примерно 5 млн ффунтов стерлингов против 50 тыс. ффунтов стерлингов первоначального бюджета кампании [16]. В 2009 г. «Невероятная Индия» выиграла международную премию в сфере туризма World Travel Awards как лучшая кампания года [13]

В 2008 г. Министерство туризма Индии разработало новую концепцию в дополнение к кампании «Невероятная Индия», получившую название «Атитхидево Бхава», что в переводе с санскрита означает «гости как Бог». Данная концепция ориентирована на местное население, с целью обучения жителей этикету общения с иностранными туристами. "Атитхидево Бхава» стремилась к созданию понимания того, что усилия, предпринимаемые для развития туризма, позволяют сохранить наследие Индии, её культуру и гостеприимство. Эта кампания также пыталась привить чувство ответственности к туристам и укрепить доверие иностранных туристов к Индии как хорошему месту для отдыха.

Несмотря на большой успех «Невероятной Индии», кампания все же вызывала критику как со стороны иностранцев, так и местных жителей. Критике подвергались название кампании, логотипы и другие сопутствующие изображения, не соответствовавшие реалиям страны [16]. Известный индийский актер Салман Кхан высмеял кампанию в 2010 г., отметив, что пицца в «Невероятной Индии» прибывает быстрее, чем полиция или скорая помощь, а ставки кредитов на образование составляют $12 \%$, в то время как ставки на автокредиты всего $5 \%$. Другие критиковали кампанию за безосновательность постоянных заявлений о быстром экономическом росте Индии и изображении ее в качестве региональной державы при наличии 410 млн бедных [13].

В 2016 г. в рейтинге национальных брендов подготовленном британской компанией «Brand Finance» Индия заняла 7-е место, а в 2017 г. переместилась на 8-ю позицию. Она также вошла в 20-ку самых дорогостоящих брендов 2017 г., стоимость индийского бренда оценивается в 2, 056 млрд долларов. Россия в данном рейтинге заняла 17-е место со стоимостью бренда в 832 млрд долларов [20]. «Brand Finance» используют также буквенные обозначения рейтинга национальных брендов - от исключительного ААА+/AАA/AAA-, к очень сильным AA+/AA/AA- и сильным брендам A+/A/A-, до слабо развитых BBВ/BВ/B, очень слабых CCC/CC/C и в случае отсутствия бренда у страны рейтинг может варьироваться от DDD до D. Индия в данном рейтинге продвинулась от A+ в 2010 г. до АА в 2017 г.

О понимании важности национального брендинга в Индии, помимо роста стоимости индийского бренда и повышения его позиций в рейтингах, свидетельствует также ссылка на его актуальность в официальных документах. Впервые в индийской истории в материалах правительства Индии по вопросам внешней торговли на 2015-2020 гг, составленных Департаментом торговли Министерства торговли и промышленности целый раздел посвящается национальному бренду [12]. 
Одним из последних проектов, разработанных С. Анхольтом является «Рейтинг хороших стран» (The Good Country Index), целью которого является измерение вклада различных стран в достижение общего блага для всего человечества. С. Анхольт отмечает, что слово (хороший) в названии проекта не следует рассматривать как антоним слову «плохой», скорее это противопоставляется «эгоистичному». Данные для разработки рейтинга предоставляются такими международными организациями как ООН, ЮНЕСКО, Всемирный банк и т.д. Всего в рейтинге на данный момент представлены 163 страны, среди них Индия занимает 59 место. Рейтинг измеряет вклад стран по 35 параметрам, поделенных на 7 категорий, каждая из которых также имеет свой арсенал показателей Например, категория «наука и технологии» рассматривает следующие данные: количество иностранных студентов, экспорт научных журналов количество публикаций в международных журналах, количество Нобелевский премий, количество патентов в соответствии с объемом экономики По каждой из категорий страна занимает определенную позицию; по науке и технологиям Индия стоит на 67 месте, по культуре - на 57-м, по международной безопасности занимает 32 место в категории мировой порядок - 89 место, в категории планета и климат - 97 место, по процветанию и равенству - 149 место и по здоровью - 35 место. В 2016 г. в общем рейтинге Индия заняла 61 место, а до этого в 2014 г. - 81 место [23]. Данные показатели отчетливо свидетельствуют об увеличении вклада Индии в глобальное развитие мира и улучшении репутации страны.

За последние годы Индия оказала глобальное воздействие на ряд секторов в мировой экономике, в частности в сферах информационных технологий и бизнес-услуг. Индийские компании стали важнейшими игроками в области технологий, фармации и автоматики, а машиностроение и нефтехимия составили $42 \%$ экспорта в 2011 г. по сравнению с 4 \% в 2001 году [19].

"Фармация мира» (Pharmacy of the World) - так позиционирует себя Индия в рамках кампании Brand India Pharma, запущенной 21 марта 2012 г на крупнейшей фармацевтической торговой выставке в Токио и ставшей первой отраслевой бренд-кампанией [14]. Данную инициативу возглавил Фармацевтический совет по содействию экспорту (Pharmexcil), основанный в 2004 году под эгидой Министерства торговли Индии с целью продвижения индийской фармацевтической продукции на глобальный рынок. Бренд намерен создавать более широкие рыночные возможности, позиционируя индийскую фармацевтику как надежную, доступную и устойчивую. Индийская фармацевтика составляет $2,4 \%$ от мировой фармацевтической промышленности в стоимостном и $10 \%$ в натуральном выражении [8]. В 2017 2018 гт. индийский экспорт фармацевтической продукции составил более 17 млрд долларов, а к 2020 г. его планируют увеличить до 20 млрд [21].

В 2014 г. к власти в Индии пришла Бхаратия джаната парти (БДП) - Индийская народная пар- тия. В последний раз она находилась у власти в 1998-2004 гг., тогда это не принесло кардинальных изменений стране. В ходе предвыборных кампаний главным лозунгом партии становится восстановление концепции «свадеши», т.е. опоры на собственные силы. Концепция появилась еще в учении Махатмы Ганди в годы борьбы индийцев с британскими колонизаторами [2] В рамках данной концепции премьер-министр Нарендра Моди 25 сентября 2014 г. объявил о запуске новой кампании - «Делайте в Индии» (Make in India), ставшей ответом на критическую ситуацию, когда темпы экономического роста страны сильно упали, а мировые инвесторы задались вопросом является Индия риском или же возможностью [17]. Ее основной задачей является превращение Индии в глобальный производственный центр, создав рабочие места в 25 секторах экономики [11]. Н. Моди самолично выбрал и эмблемы для новой кампании: колесо (чакра) Ашоки, изображенное на индийском флаге - символ движения и прогресса - и лев - животное, изображенное на гербе страны, символизирующее силу и мощь. Премьер-министр обратился ко всем с призывом: «Я говорю миру: делайте в Индии! Продавайте где угодно, но производите здесь. У нас есть для этого и мастерство, и талант!» [25]. Действительно, у Индии есть ряд преимуществ для привлечения инвесторов, такие как высокая численность трудоспособного населения, к тому же владеющая английским языком и быстрая интеграция национальной экономики в мировую, но коррупция, недостаточно развитая юридическая защита инвесторов и ряд других причин нередко препятствуют более широкому притоку иностранных капиталов в страну.

Однако это не мешает Индии занимать третье место среди глобальных систем развития стартапов, уступая лишь США и Великобритании. По оценкам научных сотрудников Института мировой экономики и международных отношений РАН в Индии такого рода бизнес пользуется еще и общественным признанием, здесь легче получить стартовый капитал, действуют наряду с заемным банковским капиталом бизнес-ангелы ${ }^{1}$, в основном зарубежные. Стартапы вносят разнообразие в структуру экономики Индии, делают ее более мобильной, создают новые возможности для занятости населения [4]

«Делайте в Индии» (Make in India) предусматривает формирование благоприятных условий для иностранных предприятий, переносящих производство в Индию, а также поддержку индийского производства, нацеленного на экспорт, под девизом: IT + IT = IT (Indian Talent + Indian Technology = India Tomorrow) [4]. Что же касается товаров, произведенных непосредственно в Индии, для них Н. Моди определил следующую формулу: «Ноль десректов, ноль эффектов» (zero defect, zero effect), где ноль дефектов подразумевает создание качественной продукции, а ноль

1 Здесь: частный венчурный инвестор, обеспечивающий финансовую и экспертную поддержку компаний на ранних этапах развития. 
эффектов исключает негативное воздействие на окружающую среду при ее производстве [9].

В том же 2014 г 2 октября Нарендра Моди запустил миссию «Чистая Индия» (Swachh Bharat Abhiyan (SBA), или Clean India Mission), целью которой является очистка улиц, дорог и инфраструктуры городов и сельских районов Индии, а также строительство 90 млн. туалетов в сельских областях до 2 октября 2019 г., в честь 150-летия со дня рождения Махатмы Ганди. Для ознакомления мировой общественности о содержании новой миссии в Индии, в 2017 г. снимается художественный фильм “Туалет: история любви» (Toilet: Ek Prem Katha), посвященный данной кампании, собравший в мировом прокате 46 млн. долларов [24]

15 июля 2015 г. в стране запускается другая кампания под названием Skill India, ее целью является обучение более 400 млн. индийцев различным практическим навыкам к 2022 г. [22]. Великобритания заключила партнерское соглашение с Индией в рамках данной программы. Стороны принимают обязательство достижения взаимного признания британской и индийской квалификаций. Несколько британских компаний взяли на себя обязательство поддерживать развитие навыков в Индии. Совместно с британским правительством и британскими предприятиями будут созданы новые «Центры передового опыта» в ключевых секторах, начиная с центра автомобильной инженерии в Пуне, говорится в совместном заявлении, опубликованном после переговоров между двумя лидерами [18].

Одной из сфер, охваченных данной кампанией, стала кожевенная промышленность. Так, по состоянию на 15 февраля 2016 г. в рамках «Программы развития индийской кожи» 51216 молодых людей прошли обучение в течение 100 дней. В последующем планируется ежегодно обучать 1 млн 44 тыс. молодых людей. Дпя улучшения инфраструктуры образования создаются четыре новых отделения «Института дизайна и разработки обуви" - в Хайдарабаде, Патне, Бануре и Анклешваре. Промышленность в стране испытывает острую нехватку квалифицированных кадров, и большинство прошедших обучение сразу поглощается отраслью [27]. Таким образом, данный проект позволит устранить одну из причин непривлекательности обувной промышленности Индии для иностранных инвесторов, а именно недостаток квалифицированной рабочей силы.

Помимо того, чтобы превратить Индию в промышленный, фармацевтический и туристический центры, власти страны стремятся создать лучшие условия для развития бизнеса, предпринимательства, инноваций. С этой целью правительство страны 16 января 2016 г. запустило программу “Стартап Индия», ее задачей является превращение индийской нации из «ищущих работу» в «создающих рабочие места». Важнейшие пункты программы включают: сокращение сборов за регистрацию патентов на $80 \%$; изменения в Законе о банкротстве, в соответствии с которыми упрощаются условия выхода из бизнеса, а также ускоряется регистрация стартапов через мобиль- ное приложение, освобождение от проверок на соответствие трудовому законодательству и законодательству по защите окружающей среды, а также уплаты налога на прирост капитала и других видов налогообложения сроком на три года По словам премьер-министра Индии, на данный проект правительство намерено выделить около 370 млн долларов ежегодно в течение четырех лет [5]. Н. Моди утверждает «В стартапах, технологиях и инновациях я вижу увлекательные и эффективные инструменты для трансформации Индии и создания рабочих мест для нашей молодежи» [6].

Кроме туризма, экспорта, инвестиций, людских ресурсов, С. Анхольт отмечает культуру и культурное наследие отдельным пунктом своего шестиугольника брендинга. Несомненно, в данном аспекте у Индии есть огромные преимущества. Это страна, где зародились древнейшие цивилизации и санскритская письменность, где возникли буддизм - первая мировая религия, йога - одна из самых популярных духовных практик и многое другое. Культурное наследие активно используется в качестве ресурсов мягкой силы и для создания привлекательного имиджа страны. Одним из таких мероприятий на глобальном уровне стало утверждение Генеральной Ассамблеей $\mathrm{OOH}$ в 2014 г. резолюции, предложенной Индией о праздновании Международного дня йоги ежегодно 21 июня, поскольку это самый длинный день в году [3]. Министр иностранных дел Индии Сушма Сварадж на одной из пресс-конференций в 2015 г заявила: «Йога - это мягкая сила Индии, и благодаря этой мягкой силе весь мир может быть одной глобальной деревней, и насилие может быть устранено с помощью такого мира» [26]. Политика мягкой силы Индии опирается на богатое культурное наследие, традиции и ценности, которые также находят свое отражение в процессе конструирования национального бренда. К примеру, Индия неизменно представляется как «самая большая демократия в мире», именно так часто называют республику в своих выступлениях индийские политики и дипломаты, тонко намекая на авторитаризм Китая - одного из самых влиятельных конкурентов Индии.

Таким образом, изучение национальных брендов и отдельных суббрендов приобретает популярность в современной научной среде. Как и на рынке, ученые-экономисты изучают потребительские вкусы и предпочтения, на основе чего производители строят стратегию производства, разработчики национальных брендов опираются на суждения ученых и экспертов, которые изучают механизмы действия национальных брендов, следят за изменениями их стоимости и других рейтинговых показателей. Изучение брендов, несомненно, требует междисциплинарного подхода, поскольку объект исследования находится на стыке экономики, политологии, социологии и других научных направлений. Для успешного осуществления задачи формирования и продвижения бренда ученым и стратегам необходимо действовать сообща, реально оценивая свои 
возможности и ресурсы в целях создания максимально привлекательного, при этом соответствующего действительности, имиджа.

Так, не вызывает сомнение наличие в Индии огромного потенциала и ресурсов, предоставляющих правительству широкий простор для разработки национального бренда. В то же время при таком разнообразии средств зачастую довольно сложно выделить главное и не упустить детали в процессе разработки стратегии национального брендинга. На данном этапе у Индии неплохие показатели, которые во многом обусловлены активной политикой нынешнего премьер-министра, од- нако делать какие-либо прогнозы сложно в связи с грядущими парламентскими выборами в 2019 г. Рассмотренные выше кампании определенно способствовали улучшению репутации страны, каждая из них дополняет другую, и несмотря на разные задачи упомянутых проектов, они преследуют единую цель - создать уникальный, неповторимый имидж собственной нации, который бы соответствовал всем красивым слоганам и логотипам, а также отвечал требованиям индийского общества - позволив развеять различные стереотипы об индийской культуре и выбраться на новый уровень международного признания.

\section{Источники и литература}

1. Кобякина О. Е. Брендинг территорий: национальная кухня как один из атрибутов бренда страны (на примере Дании, Швеции, Латвии и России) // Электронный научный журнал «Медиаскоп» URL: http://www.mediascope.ru/1614 (Дата обращения: 05.07.2018).

2. Круть В. Г. Индия: концепция «свадеши» в условиях глобализации // Международный студенческий научный вестник. 2016. №2. URL: http://www.eduherald.ru/ru/article/view?id=15139 (Дата обращения: 16.07.2018).

3. OОН назначила Международный день йоги // Lenta.Ru (12 декабря 2014) URL: https://lenta.ru/news/2014/12/12/ yoga/ (Дата обращения: 10.07.2018).

4. Производите здесь // Эксперт Урал (Июль 2016) URL: http://expert.ru/ural/2016/27/proizvodite-zdes/ (Дата oбpaщения: 16.07.2018).

5. Стартапы в Индии будут освобождены от налогов URL: https://offshorewealth.info/offshore-business-abroad/ startups-in-india-will-be-taxfree/ (Дата обращения: 17.07.2018)

6. Страна стартапов // BRICS Business magazine URL: https://bricsmagazine.com/ru/articles/strana-startapov (Дата обращения: 17.07.2018)

7. Anholt S. Competitive Identity: a new model for the brand management of nations, cities and regions. New York: Palgrave Macmillan, 2007.147 p.

8. Brand India Pharma: Promoting Indian Pharma Industry \& Companies Globally URL: https://www.brandindiapharma.in/ (Accessed: 11.07.2018).

9. Ecologists cheer Modi's 'zero defect, zero effect' slogan // The Times of India (Aug 16, 2014) URL: https://timesofindia. indiatimes.com/home/environment/developmental-issues/Ecologists-cheer-Modis-zero-defect-zero-effect-slogan/ articleshow/40312809.cms (Accessed: 16.07.2018).

10. Fan Y. Branding the nation: towards a better understanding // Place Branding and Public Diplomacy. 2010. №6 (2). P. 97-103.

11. Focus on Make In India, Ministry Of Heavy Industries \& Public Enterprises // Business Stadard (September 2014) URL: https://www.business-standard.com/article/government-press-release/focus-on-make-in-india-114092501206_1.html (Accessed: 16.07.2018).

12. Foreign Trade Policy (1st April 2015 - 31st March 2020) // http://dgft.gov.in/exim/2000/ftp2015-20E.pdf (Accessed: 16.07.2018).

13. Impacts of Incredible !ndia campaigning on tourism. URL: https://ru.scribd.com/document/77035533/Incredible-IndiaFinal (Accessed: 16.07.2018).

14. Interview with Aparna Sharma on Nation Branding in India // The Place Brand Observer (July, 2015) URL: https:// placebrandobserver.com/interview-aparna-sharma/ (Accessed: 16.07.2018).

15. Kant A. Branding India: An Incredible story. Uttar Pradesh, India: Harper Collins, 2009. 267 p

16. Kerrigan F., Shivanandan Jy., Hede A-M. Nation Branding: A Critical Appraisal of Incredible India // Journal of Macromarketing. № 32 (3). P. 319-327.

17. Make in India // Official web site. URL: http://www.makeinindia.com/home (Accessed: 16.07.2018)

18. Modi in UK: 11 British companies support skill development in India // DNA: Daily News and Analysis (November 2015) URL:http://www.dnaindia.com/business/report-modi-in-uk-11-british-companies-support-skill-development-in-india-2144786 (Accessed: 16.07.2018).

19. Nation Brands 100: The Brand Finance report on the 100 most valuable Nation Brands // Brand Finance (November 2011) URL: http://brandfinance.com/images/upload/bfnb_100_2011_web_sp.pdf (Accessed: 16.07.2018).

20. Nation Brands 2017: The annual report on the world's most valuable nation brands // Brand Finance (October 2017) URL: http://brandfinance.com/images/upload/bf_nation_brands_2017.pdf (Accessed: 16.07.2018).

21. Pharma exports can cross $\$ 20$ bn by 2020 : Chief of Pharmexcil // The Economic Times (May 2018) URL: https:// economictimes. indiatimes.com/industry/healthcare/biotech/pharmaceuticals/pharma-exports-can-cross-20-bn-by-2020chief-of-pharmexcil/articleshow/64055966.cms '(Accessed: 16.07.2018).

22. PM Modi Launches Skill India Initiative That Aims to Train 40 Crore People // NDTV (July 2015) URL: https://www.ndtv. com/india-news/pm-modi-launches-skill-india-initiative-that-aims-to-train-40-crore-people-781897 (Accessed: 16.07.2018)

23. The Good Country Index results URL: https://goodcountry.org/index/results (Accessed: 16.07.2018).

24. Toilet: Ek Prem Katha trumps Baahubali 2 in China; becomes Akshay Kumar's first film to cross Rs $300 \mathrm{cr}$ mark worldwide (June 2018) URL: https://www.firstpost.com/entertainment/toilet-ek-prem-katha-trumps-baahubali-2-in-chinabecomes-akshay-kumars-first-film-to-cross-rs-300-cr-mark-worldwide-4530341.html (Accessed: 16.07.2018). 
25. Top 5 quotes from Narendra Modi's Make in India campaign URL: http://www.india.com/buzz/narendra-modis-make-inindia-campaign-top-5-quotes-from-the-pms-make-in-india-speech-157589/ (Accessed: 16.07.2018).

26. Transcript (English Interpretation) of Joint Press Conference by ExternalAffairs Minister and Minister of State (I/C)AYUSH on Celebration of International Day of Yoga (June 9, 2015) // Ministry of External Affairs, Government of India. official web site URL: http://mea.gov.in/media-briefings.htm?dtl/25359/Transcript+English+Interpretation+of+Joint+Press+Conference + by $+E$ xternal+Affairs+Minister+and+Minister+of+State+IC+AYUSH+on+Celebration+of+International+Day+of+Yoga+June+9+2015 (Accessed: 16.07.2018)

27. Why Make in India may be the answer to India's unemployment puzzle // The Economic Times (February 16 2016) URL: https://economictimes.indiatimes.com/jobs/why-make-in-india-may-be-the-answer-to-indias-unemployment-puzzle/ articleshow/51002694.cms (Accessed: 16.07.2018).

\section{References}

1. Kobyakina O. E. Brending territorij: nacionalnaya kuhnya kak odin iz atributov brenda strany (na primere Danii SHvecii Latvii i Rossii) (Branding of Territories: National Cuisine as One of the Attributes of the Country's Brand (by the Example of Denmark, Sweden, Latvia and Russia) // MediaScope URL: http://www.mediascope.ru/1614 (Accessed: 05.07.2018). (In Russian).

2. Krut V. G. Indiya: koncepciya svadeshi v usloviyah globalizacii (India: the Concept of "Swadeshi" in the Conditions of Globalization) // International student scientific bulletin. 2016. No.2. URL: http://www.eduherald.ru/en/article/view?id=15139 (Accessed: 07.06.2018) (In Russian).

3. OON naznachila Mezhdunarodnyj den jogi (UN Appointed International Yoga Day) // Lenta.Ru (December 12, 2014) URL: https://lenta.ru/news/2014/12/12/yoga/ (Accessed: 07.10.2018) (In Russian).

4. Proizvodite zdes (Produce Here) // Expert Ural (July 2016) URL: http://expert.ru/ural/2016/27/proizvodite-zdes/ (Accessed: 07.06.2018) (In Russian)

5. Startapy v Indii budut osvobozhdeny ot nalogov (Startups in India will be Exempt from Taxes) URL: https://offshorewealth. info/offshore-business-abroad/startups-in-india-will-be-taxfree/ (Accessed: 17.07.2018) (In Russian).

6. Strana startapov (Country of Start-ups) // BRICS Business magazine. URL: https://bricsmagazine.com/en/articles/ strana-startapov (Accessed: 17.07.2018) (In Russian).

7. Anholt S. Competitive Identity: a new model for the brand management of nations, cities and regions. New York: Palgrave Macmillan, 2007. 147 p.

8. Brand India Pharma: Promoting Indian Pharma Industry \& Companies Globally URL: https://www.brandindiapharma.in/ (Accessed: 11.07.2018)

9. Ecologists cheer Modi's 'zero defect, zero effect' slogan // The Times of India (Aug 16, 2014) URL: https://timesofindia. indiatimes.com/home/environment/developmental-issues/Ecologists-cheer-Modis-zero-defect-zero-effect-slogan/ articleshow/40312809.cms (Accessed: 16.07.2018).

10. Fan Y. Branding the nation: towards a better understanding // Place Branding and Public Diplomacy. 2010. №6 (2). P. 97-103.

11. Focus on Make In India, Ministry Of Heavy Industries \& Public Enterprises // Business Stadard (September 2014) URL: https://www.business-standard.com/article/government-press-release/focus-on-make-in-india-114092501206_1.html (Accessed: 16.07.2018)

12. Foreign Trade Policy (1st April 2015 - 31st March 2020) // http://dgft.gov.in/exim/2000/ftp2015-20E.pdf (Accessed: 16.07.2018)

13. Impacts of Incredible India campaigning on tourism. URL: https://ru.scribd.com/document/77035533/Incredible-IndiaFinal (Accessed: 16.07.2018).

14. Interview with Aparna Sharma on Nation Branding in India // The Place Brand Observer (July, 2015) URL: https:// placebrandobserver.com/interview-aparna-sharma/ (Accessed: 16.07.2018).

15. Kant A. Branding India: An Incredible story. Uttar Pradesh, India: Harper Collins, 2009. 267 p.

16. Kerrigan F., Shivanandan Jy., Hede A-M. Nation Branding: A Critical Appraisal of Incredible India // Journal of Macromarketing. № 32 (3). P. 319-327.

17. Make in India // Official web site - URL: http://www.makeinindia.com/home (Accessed: 16.07.2018).

18. Modi in UK: 11 British companies support skill development in India // DNA: Daily News and Analysis (November 2015) URL:http://www.dnaindia.com/business/report-modi-in-uk-11-british-companies-support-skill-development-in-india-2144786 (Accessed: 16.07.2018).

19. Nation Brands 100: The Brand Finance report on the 100 most valuable Nation Brands // Brand Finance (November 2011) URL: http://brandfinance.com/images/upload/bfnb_100_2011_web_sp.pdf (Accessed: 16.07.2018).

20. Nation Brands 2017: The annual report on the world's most valuable nation brands // Brand Finance (October 2017) URL: http://brandfinance.com/images/upload/bf_nation_brands_2017.pdf (Accessed: 16.07.2018).

21. Pharma exports can cross $\$ 20$ bn by 2020 : Chief of Pharmexcil // The Economic Times (May 2018) URL: https:// economictimes.indiatimes.com/industry/healthcare/biotech/pharmaceuticals/pharma-exports-can-cross-20-bn-by-2020chief-of-pharmexcil/articleshow/64055966.cms `(Accessed: 16.07.2018).

22. PM Modi Launches Skill India Initiative That Aims to Train 40 Crore People // NDTV (July 2015) URL: https://www.ndtv. com/india-news/pm-modi-launches-skill-india-initiative-that-aims-to-train-40-crore-people-781897 (Accessed: 16.07.2018).

23. The Good Country Index results URL: https://goodcountry.org/index/results (Accessed: 16.07.2018).

24. Toilet: Ek Prem Katha trumps Baahubali 2 in China; becomes Akshay Kumar's first film to cross Rs $300 \mathrm{cr}$ mark worldwide (June 2018) URL: https://www.firstpost.com/entertainment/toilet-ek-prem-katha-trumps-baahubali-2-in-chinabecomes-akshay-kumars-first-film-to-cross-rs-300-cr-mark-worldwide-4530341.html (Accessed: 16.07.2018).

25. Top 5 quotes from Narendra Modi's Make in India campaign URL: http://www.india.com/buzz/narendra-modis-make-inindia-campaign-top-5-quotes-from-the-pms-make-in-india-speech-157589/ (Accessed: 16.07.2018). 
26. Transcript (English Interpretation) of Joint Press Conference by External Affairs Minister and Minister of State (I/C) AYUSH on Celebration of International Day of Yoga (June 9, 2015) // Ministry of External Affairs, Government of India. official web site. URL: http://mea.gov.in/media-briefings.htm?dtl/25359/Transcript+English+Interpretation+of+Joint+Press+Conference+by+E xternal+Affairs+Minister+and+Minister+of+State+|C+AYUSH+on+Celebration+of+International+Day+of+Yoga+June+9+2015 (Accessed: 16.07.2018).

27. Why Make in India may be the answer to India's unemployment puzzle // The Economic Times (February 162016 ) URL: https://economictimes.indiatimes.com/jobs/why-make-in-india-may-be-the-answer-to-indias-unemployment-puzzle/ articleshow/51002694.cms (Accessed: 16.07.2018). 